\title{
Lean transformation to reduce costs in healthcare: A public hospital case in Turkey
}

\author{
Alkin Yurtkuran*1, Duygu Özdemir ${ }^{1}$, D. Merih Yurtkuran ${ }^{2}$, Erdal Emel ${ }^{1}$ \\ ${ }^{1}$ Dept. of Industrial Engineering, Faculty of Engineering, Uludag University, Bursa, Turkey \\ ${ }^{2}$ Faculty of Medicine, Uludag University, Bursa, Turkey
}

Received: April 27, 2017

DOI: $10.5430 /$ jha.v6n $4 \mathrm{p} 10$
Accepted: May 27, 2017

Online Published: June 7, 2017

\begin{abstract}
Until recently, hospitals have adapted a series of quality standards to improve the quality of their services. However, these standards do not provide any cost reduction that is worth mentioning within which qualified personnel, material and indirect costs are already very high. To overcome this problem, lean production techniques have been integrated to the healthcare processes in the last few years. This study aimed to reduce costs by both improving and shortening the time of Social Security Instituition (SSI) based invoicing processes of a public hospital in Bursa, Turkey during the period of 2013-2014. To accomplish this goal various lean tools such as value stream mapping, poka-yoke, kaizen and standardization were presented and implemented. For validation purposes, montly SSI cuts, total income and process times before and after the lean transformation were analysed and compared. Furthermore, patient satisfaction surveys were carried out in order to investigate the negative effects of cost oriented lean studies. Results reveal that a clear improvement in total income is achievable, while maintaining the patient satisfaction levels. In this case, an eight percent improvement in SSI cuts resulting in a clear improvement on total income values has been obtained. Findings indicate that implementing lean tools on hospital processes is an effective way to reduce the healthcare costs while maintaining the patient satisfaction levels. The results of this study will stimulate the research in adopting lean techniques not only for patient satisfaction, but also for cost reduction purposes in hospitals.
\end{abstract}

Key Words: Lean management, Cost-efectiveness, Healthcare quality improvement

\section{INTRODUCTION}

The sustainability of healthcare services provided as a public duty of states is dependent upon a non-increasing ratio of healthcare expenditures to the gross national product. During the period of 1999-2015, the public and private healthcare expenditures in Turkey have increased four times based on US Dollars. While in 1999, 11.7 million US Dollars had been spent for healthcare, this amount was up to 43.3 million US Dollars in 2014..$^{[1]}$ According to the World Health Organization, ${ }^{[2]}$ the ratio of healthcare expenditures to the gross domestic product increased from 4.77\% in 1999 to
$5.41 \%$ in 2014. Moreover, the annual growth rate of public expenditures on healthcare (per capita) increased by an average of $1.5 \%$ between 1999 and 2014. ${ }^{[3]}$ Currently 8\% of the population in Turkey is above 65 years of age and this ratio is expected to increase up to $10 \%$ in 2023 and $21 \%$ in 2050, causing an additional growth in healthcare expenditures. ${ }^{[1]}$ In summary, while increases in healthcare expenditures create a burden for the national budgets, basically the healthcare service providers play the most significant role in helping the governments to lessen the burden on the budgets.

Until recently, hospitals have adapted a series of standards

\footnotetext{
${ }^{*}$ Correspondence: Alkin Yurtkuran, PhD; Email: alkin@uludag.edu.tr; Address: Dept. of Industrial Engineering, Faculty of Engineering, Uludag University, Bursa, Turkey.
} 
such as ISO 9001:2000 quality management system or Joint Commission International accreditation to improve the quality of their services. However, these standards do not provide any cost reduction that is worth mentioning within which qualified personnel and material costs are already very high. Therefore, a new approach should be developed for hospitals to manage their high costs without compromising the quality of their services. At this point, the requirement of lean hospital applications comes into effect. Within the scope of these applications, lean methods and techniques should be utilized in hospitals together with necessary process improvements in order to reduce the related governmental expenditures.

Lean thinking had originally been developed in Toyota Motor Corporation in Japan, in order to reduce the lead time in production by eliminating non-value added activities. The core idea behind lean thinking is the "customer value" and the basic aim is to maximize the customer value while minimizing the waste. ${ }^{[4,5]}$ Today, lean thinking tools and techniques are being used in production and service industry and healthcare services.

In this study, the lean transformation of a hospital has been practiced at Atatürk Rehabilitation Application and Research Center of Uludağ University, Bursa, Turkey. The main goal of this transformation is to reduce the high costs of university hospital operations that pose a burden for the government and develop a more productive and efficient institution by improving and shortening the time of invoicing processes. To accomplish this goal, a lean thinking based study has been carried out for a six-month period, which is composed of the following steps: (1) identification of value and nonvalue added activities to reduce wastes, (2) standardization of tasks, (3) finding proactive solutions for the problems and (4) mistake-proofing (poka-yoke). In these implementation steps, the lean management techniques such as process flow diagrams, value stream mapping, fishbone diagrams (Ishikawa diagrams) to identify potential factors causing quality defects and check lists for mistake-proofing and kaizen studies have been used.

The remainder of this paper is structured as follows: Section 2 reviews the literature of lean applications in healthcare; Section 3 introduces the methodology; results of the study are presented in Section 4 and finally Section 5 concludes the paper.

\section{Literature REVieW}

Lean approaches had been originally developed for the automotive and manufacturing industry. However, in order to increase their efficiency and productivity, the service industry, especially the hospitals have been wise to adapt to lean Published by Sciedu Press transformation by applying similar lean techniques to their processes. ${ }^{[6]}$ Lean is an approach which improves healthcare service quality by eliminating faults and decreasing patient waiting times through effective use of available resources. ${ }^{[7]}$ In this section, a literature review of five lean transformation tools that are used in this study are given and the corresponding lean healthcare applications are summarized.

\subsection{Value stream mapping}

Value stream refers to the aggregation of all value added and non-value added activities that are required to produce a product through production lines. Value stream mapping is a technique which facilitates to comprehend the material and information flow along the value stream through which the product passes. ${ }^{[8,9]}$ Value stream mapping also provides the visualization of information between each process step and the delay time between two steps by simply identifying the duration of non-value added activities. ${ }^{[6,8]}$ Teichgräber and de Bucourt ${ }^{[10]}$ have applied value stream mapping in an interventional radiology department in order to reduce the non-value added activities in an endovascular stent procurement process. Snyder, Paulson ${ }^{[11]}$ used the same technique in order to eliminate the document search requirement for the follow-up visits of patients in a clinic. Furthermore, Dickson, Singh $^{[12]}$ used standard task methodology along with value stream mapping in order to analyze the existing situation in emergency services to remove the non-value added steps and to improve other steps. Cima, Brown ${ }^{[13]}$ used value stream mapping along with six sigma methods to increase the efficiency of operation rooms at a medical center that provides third level patient treatment services. Dickson, Anguelov ${ }^{[14]}$ have identified value added and non-value added steps for emergency services of hospitals and made improvements by doing kaizens along with value stream mapping. In another study, value stream mapping was implemented with simulation to reduce the patient's length of stay in the physical therapy and rehabilitation department of a public hospital in Turkey. ${ }^{[15]}$ Weigel, Suen ${ }^{[16]}$ developed a quality improvement curriculum for internal medicine residents at Boston Medical Center, which includes lean techniques such as; identifying non-value added tasks and mudas in process maps and creating fishbone diagrams. Moreover, majority of the lean healthcare studies have focused on applying value stream mapping as the most important tool of lean thinking. ${ }^{[17-22]}$

\subsection{Standardization of tasks}

Based on Graban, ${ }^{[7]}$ standardization of tasks is the only way to accomplish a task safely with proper results at high quality. A standardized task is more than a completion of assignments with given program details. Definition of standardized tasks also provides re-evaluation of the tasks assigned to 
the employees. ${ }^{[9]}$ Waldhausen, Avansino ${ }^{[23]}$ used task standardization and $5 \mathrm{~S}$ method to reduce variability and increase efficiency and patient satisfaction in surgery clinics at Seattle Children's Hospital. On the other hand, LaGanga ${ }^{[24]}$ utilized standardized tasks method at 18 outpatient treatment clinics to increase the outpatient treatment capacity of the same hospital.

\subsection{Mistake-proofing (poka-yoke)}

Check lists are frequently used at hospitals as a part of process improvement studies to reduce the number of mistakes. $^{[7]}$ Raab, Andrew-JaJa ${ }^{[25]}$ utilized checklists in order to increase the test quality by decreasing test errors in Magee Women's Hospital clinical laboratories. Spear ${ }^{[26]}$ also worked on designing checklists to reduce discharge durations of inpatients and increase the efficiency of healthcare staff.

\subsection{Kaizen}

$\mathrm{Ohno}^{[4]}$ defined Kaizen as a non-bureaucratic daily procedure in which simple improvements are applied continuously. The procedure requires employees to involve in a rapid improvement cycle thus encouraging them to take responsibility for improving the processes they are part of. The employees should be supported for proposing new ideas directly to their colleagues or supervisors. ${ }^{[7]}$ Although most of the lean healthcare studies include kaziens, the studies of Spear ${ }^{[26]}$ and Yousri, Khan ${ }^{[27]}$ are distinguishable among others. Spear ${ }^{[26]}$ applied kaizen in Life Care Hospital, Monongahela Valley Hospital, UPM Health Centre and Allegheny General Hospital with the intention of remedy non-complete tests of the patients before surgery, improving on-time delivery of the medicine to the patients and increasing awareness in hygiene. Besides, Yousri, Khan ${ }^{[27]}$ conducted kaizen studies in Goodhope Hospital to improve the quality of the service that is given to patients with femur fracture. Vegting, van Beneden ${ }^{[28]}$ introduced several kaizens to reduce the costs of unnecessary diagnostic tests.

For a detailed literature review of lean applications in healthcare, readers can refer to studies of Brandao de Souza, ${ }^{[29]}$ Burgess and Radnor, ${ }^{[30]}$ Holden, ${ }^{[31]}$ Mazzocato, Savage, ${ }^{[32]}$ Nicolay, Purkayastha, ${ }^{[33]}$ Toussaint and Berry ${ }^{[34]}$ and Costa and Godinho Filho. ${ }^{[35]}$

In summary, while the majority of lean healthcare studies is focused on improving the quality of healthcare services, only Vegting, van Beneden ${ }^{[28]}$ has implemented lean approaches with a main objective to reduce the costs of healthcare services provided. With the help of aforementioned literature review, the main contributions of the proposed study can be stated as follows: (1) main focus is cost reduction while retaining the patient satisfaction level, (2) various lean tools are implemented to different processes of an hospital.

\section{METHOD}

\subsection{The hospital}

This study has been conducted in Atatürk Rehabilitation Application and Research Center (ARUAM) at Uludağ University, Bursa Turkey. At ARUAM, diagnosis and therapy of rheumatic and musculoskeletal system diseases are being provided in addition to outpatient rehabilitation services for neurological, orthopedic and plastic surgery with 27.7 fulltime equivalent staff approximately. In accordance with the diagnosis, physical therapy, medical treatment or a combination of both with hydrotherapy are applied to outpatients and inpatients. Furthermore, radiology and biochemistry laboratory services are provided. The medical center is a 25-bed hospital for inpatients in addition to three polyclinics used for examination of outpatients having an average rate of 120 outpatients/day and three treatment rooms for both outpatients and inpatients. Furthermore, there are three treatment rooms for outpatients and inpatients, a therapeutic pool and several baths used for hydrotherapy with eight resting cabinets.

ARUAM is a third level service provider in the healthcare system of Turkey and part of a university hospital operating under the structure of Healthcare and Research Center of Uludağ University (SUAM). University hospitals along with the specialist training hospitals operating under the ruling of Ministry of Health of Turkey provide the most advanced level of healthcare services in the country. These hospitals also play a very important role in training the medical school students. $^{[36]}$

The income of university hospitals obtained from patient treatment services is critical for the sustainability and the quality of overall healthcare services. It is important that, the services provided to the patients who are fully covered by the Social Security Institution (SSI) must be fully paid back. The SSI is a state organization, which provides healthcare insurance for all citizens. In order to attain a full pay back, recording and reporting of the pre-defined patient treatment processes must be strictly documented to satisfy the regulations of the SSI.

In general, the sources of income for ARUAM are as follows:

(1) University revolving fund business (URFB);

(2) State budget;

(3) Grants or donations from externals.

ARUAM finances it operational activities for student training and patient treatment services only partially from the state budget but mostly from the URFB income obtained directly 
from patients and/or indirectly by reimbursing from SSI. Although the grants and donations are considered as another source of income for the hospital, the share of those sources for the costs of services is minor and discontinuous. In other words, $85 \%$ of the total income is from URFB, whereas $14 \%$ and $1 \%$ of the incomes are state budget and grants or donations, respectively.

From the state budget, only personnel salaries, travel expenses, construction of facilities and fixed asset expenses are paid. On the other side, medication, medical devices, medical consumables and other consumable material costs for patient treatment processes are paid by the university revolving fund Therefore, revolving fund incomes are of utmost importance for ARUAM since the services can be sustained only with this income within the existing budgetary system. Furthermore, in case of shortage of supplementary services within the institution, additional personnel for medical, sanitary, and security tasks can be hired by the URFB.

In this process, the invoice issued by the URFB for medical services provided by ARUAM, together with the treatment details file for each patient are submitted to the SSI. However invoice submission is a time-limited process on the condition that invoices can only date back up to two months. The invoices submitted to the SSI are controlled in line with the provisions of governmental decrees for medical applications. After the inspection of files, the faulty ones are not approved and marked as non-payable or partially payable. In the past, as one of the motivations behind this study, ARUAM had found itself being unable to reimburse the majority of its service related costs filed for a period of six months due to 193 faulty files marked by SSI. A subsequent analysis by the hospital management revealed that there were significant problems and delays within the invoicing process of ARUAM inconsistent with the SSI regulations. Hence, the basis of this study has been setup in order to make the necessary research for improving the invoicing process of ARUAM.

\subsection{Lean transformation}

As indicated above, the main goal of this process improvement study is to shorten the invoicing period and reduce invoicing errors by utilizing the tools cited frequently under lean transformation projects. As the first step of this transformation, the definition of value added and non-value added activities have been identified based on process flow diagrams and value stream maps. Followed by the elimination of most of the non-value added activities through kaizen's, the new states of activities have been identified. As the second step, job descriptions have been revised and standardized after the removal of non-value added activities and tasks from job descriptions. The cause and effect diagram has been utilized to identify the basic reasons for invoicing errors and delays in process steps. Finally, poke-yoke activities such as file item checklists have been generated for the use of staff to ease their decision making within the process steps.

\subsubsection{Process flow diagrams and value stream mapping}

In this study, as an initial task, a functional process flow diagram for the invoicing process at ARUAM has been generated. In this diagram, inclusive "tracks" or "swimlanes" were used showing every personnel and relevant department responsible for each step.

\section{Before the lean transformation (current state)}

Figure 1 indicates the process flow diagram before conducting this work or in other words, the current state map. On the left side of each horizontal lane, the person or commission responsible for implementation of those tasks within the lane is introduced. In this diagram, Avicenna IT represents the software and its users at IT Department, operating in coordination with Hospital Administration and URFB, which are both responsible from the healthcare information management system at ARUAM and SUAM. Medula is the integrated nationwide information management system of the SSI, which provides access to all its stakeholders. All local transaction data collected through Avicenna system are invoiced and submitted to the Medula system by the Medula Invoice Commission based in URFB Accounting Office. In Figure 1, the process flow has been generated based on the execution order of the responsible staff. ${ }^{[36]}$

The value stream map of the existing invoicing process has been generated and depicted in Figure 2, where time is given in decimal days.

A study of the initial phase in Figure 2 reveals that, patient files are delayed for:

- 3.5 days until completion of temporary files at ARUAM IT;

- 15 days for completion of documentation control at invoice commission of SUAM;

- 2 days for completion of documentation at ARUAM IT and;

- 1 to 3 days during transportation between geographically dispersed ARUAM and SUAM;

- Patient files are held for 22.5 days until filtering decision at SUAM invoice commission;

- days for completion of documentation at ARUAM IT;

- 7 days until completion of filtering at ARUAM IT and;

- 2-4 days during transportation. 


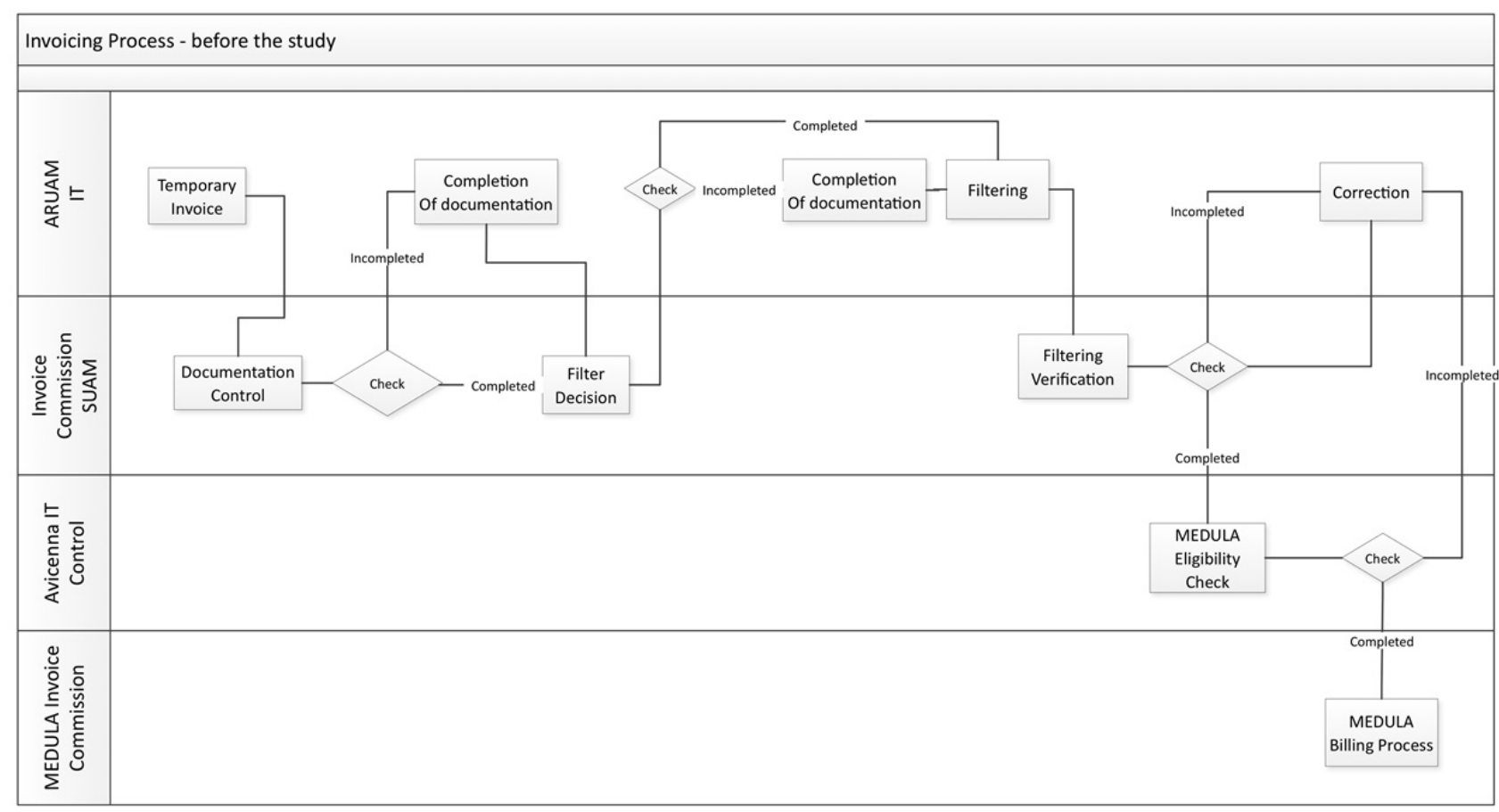

Figure 1. Process flow diagram of the invoicing process before the lean transformation

As can be seen from the last phase of Figure 2:

- Patient files are held for 2 days until filtering verification at SUAM invoice commission;

- 2 days for correction of documentation at ARUAM IT;

- 1 day for Medula eligibility check at Avicenna IT;

- 6 days until completion of Medula billing procedure and;

- 1-2 days during transportation.

Analyzing the value stream map in Figure 2, it can be easily concluded that finalizing the invoicing process takes a total of more than two months for activities, waiting and transportation. However, the invoices can only be submitted to SSI within two months time after the consumed services. Therefore, the correction of faulty invoices that cannot be completed on time results in a loss of income due to the URFB being not able to collect a large part of the invoices from SSI.

Prior to the lean transformation, there were 16 different sequences of activities based on four different decision points (DP). Total lead times have been calculated for each of 16 courses of action using the stamped time of point of entry of information at each activity recorded in Avicenna or manually. Value added, non-value added and total durations are listed for each of 16 scenarios with four different DP on a decimal day based time unit in Table 1. As indicated in Table 1, the process can be completed in an average of 67.69 and a standard deviation of 4.05 days, which shows that the lead times are at least two months.

\section{After the lean transformation (future state)}

To eliminate such a waste, it is decided to establish a new invoice commission under the cover of ARUAM, which is tasked to eliminate unnecessary material handling and personnel movement and idle times in value stream maps. For that purpose, job descriptions of the involved ARUAM personnel and the relevant process flow diagrams have been updated. The invoice control task of SUAM has been assigned to ARUAM chief nurse. Additionally, necessary on-job trainings have been provided to the nurses for their invoice control duty.

Figure 3 indicates the process flow diagram after conducting the study. Tasks such as temporary invoicing, filtering, documentation control, filtering control, documentation completion, filtering and correction as depicted in Figure 1 were all given as the current state before the lean transformation. In Figure 3, these steps are all consolidated pairwise to single steps and mostly assigned to ARUAM personnel within the future state map of this study. Therefore, it is expected to result in less processing errors and eliminate delays due to non-value added activities.

Figure 4 shows the value stream map of the process starting from the temporary invoice generation and filtering of the patient files at ARUAM IT, up to the MEDULA Billing Process. In Figure 4, time is given in decimal days similar to Figure 2. As can be seen from Figure 4, patient files are handled for: 

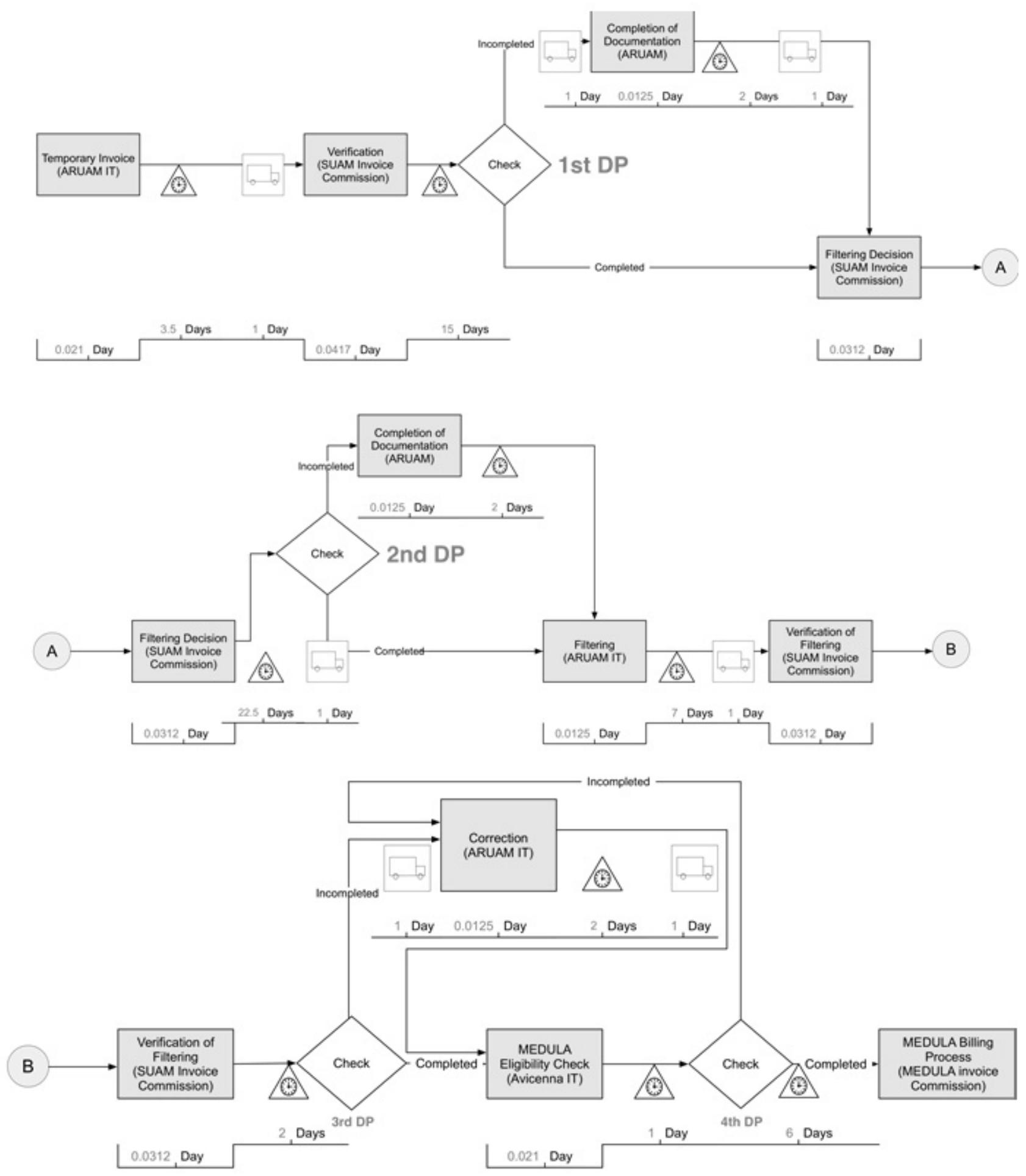

Figure 2. Value stream map before the lean transformation

- 0.5 days at ARUAM IT for temporary invoice and filtering procedures;

- 0.5 day at ARUAM invoice commission for documentation control and filtering correction procedures;

- 0.5 day at ARUAM IT for documentation completion and filtering correction procedures;
- 0.5 day at ARUAM invoice commission for control procedures and 1 day during the transportation along the process.

As can be seen from Figure 4, patient files are handled for:

- 1 day at Avicenna IT control for Medula eligibility 
check procedures;

- 1 day at ARUAM IT for correction procedure;

- 6 days for Medula invoice check-out payment procedure and;

- 2 days during the transportation along the process.

The time spent for the transportation of invoices from ARUAM to SUAM for invoice control procedure is a nonvalue added effort. With the assignment of invoice control task to ARUAM, the time spent for transportation of file from
ARUAM to SUAM has been eliminated. As a result of this elimination together with task consolidation and reductions, the duration of the process has been reduced significantly. The overall lead time improvement for the invoicing process which has been estimated over the value stream map shown in Figure 4 indicated that, the total duration is 8 to 14 days when all scenarios are considered. Consequently, the process can be completed in 2 weeks time, far less than the previous situation.

Table 1. Completion times for each probable scenario in the value stream map (see Figure 2) before the lean transformation

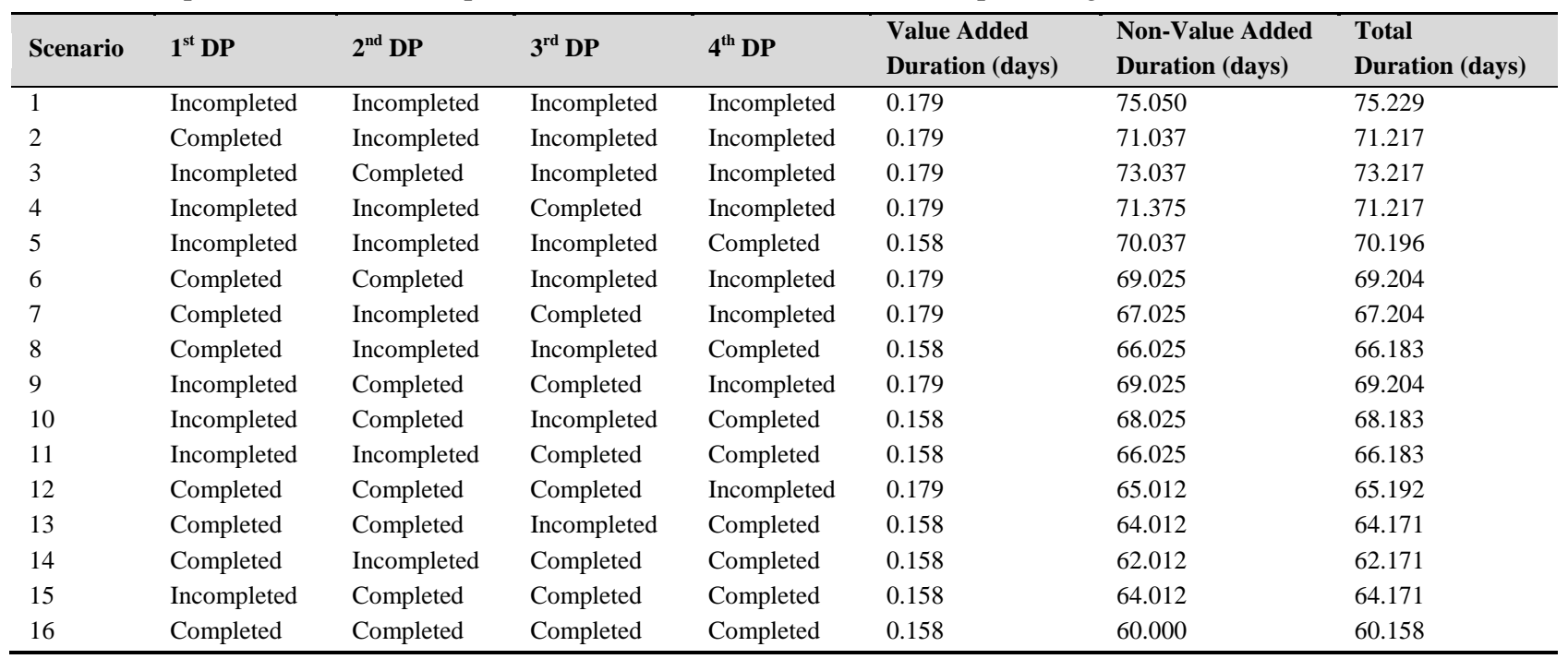

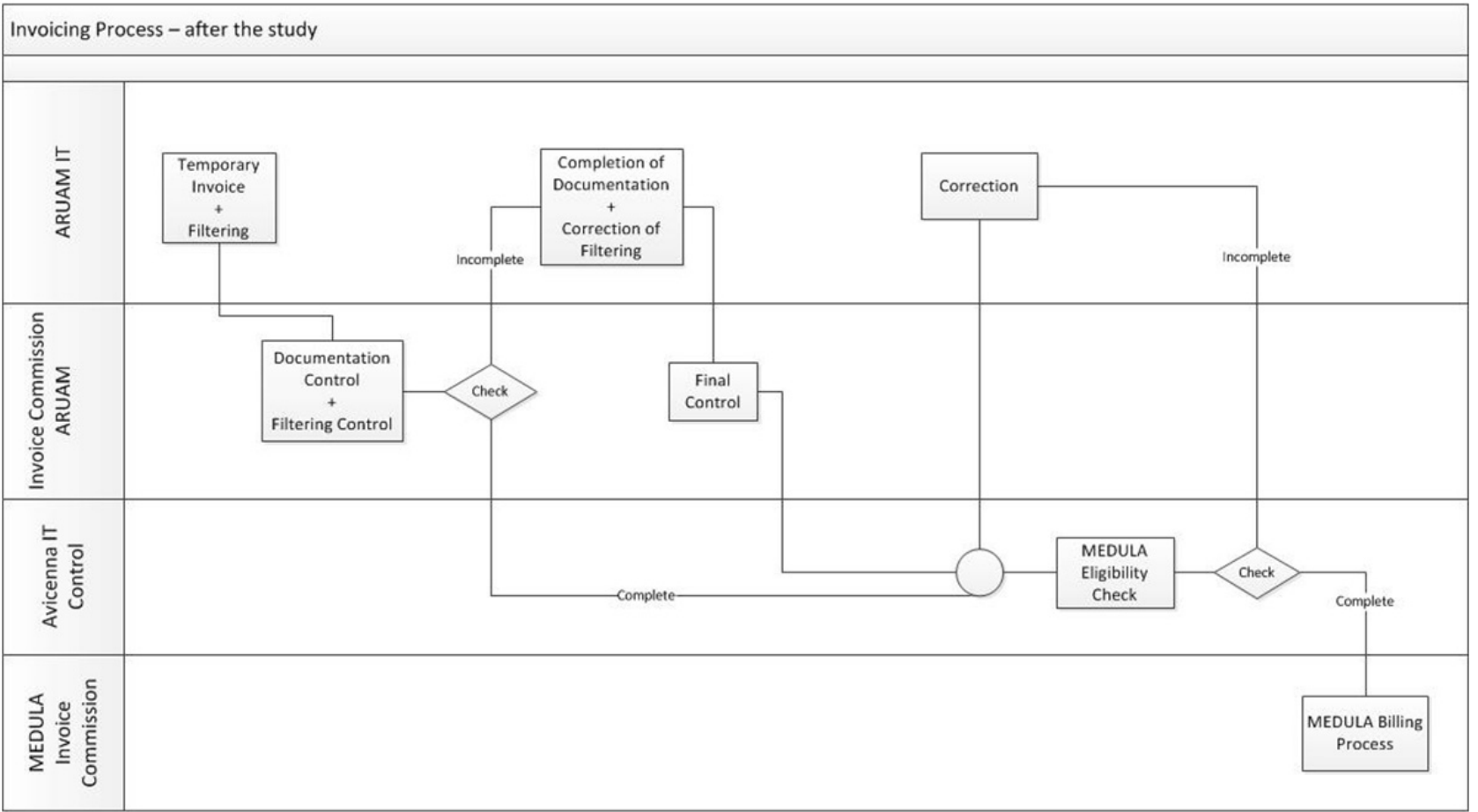

Figure 3. Process flow diagram after the lean transformation (future state) 

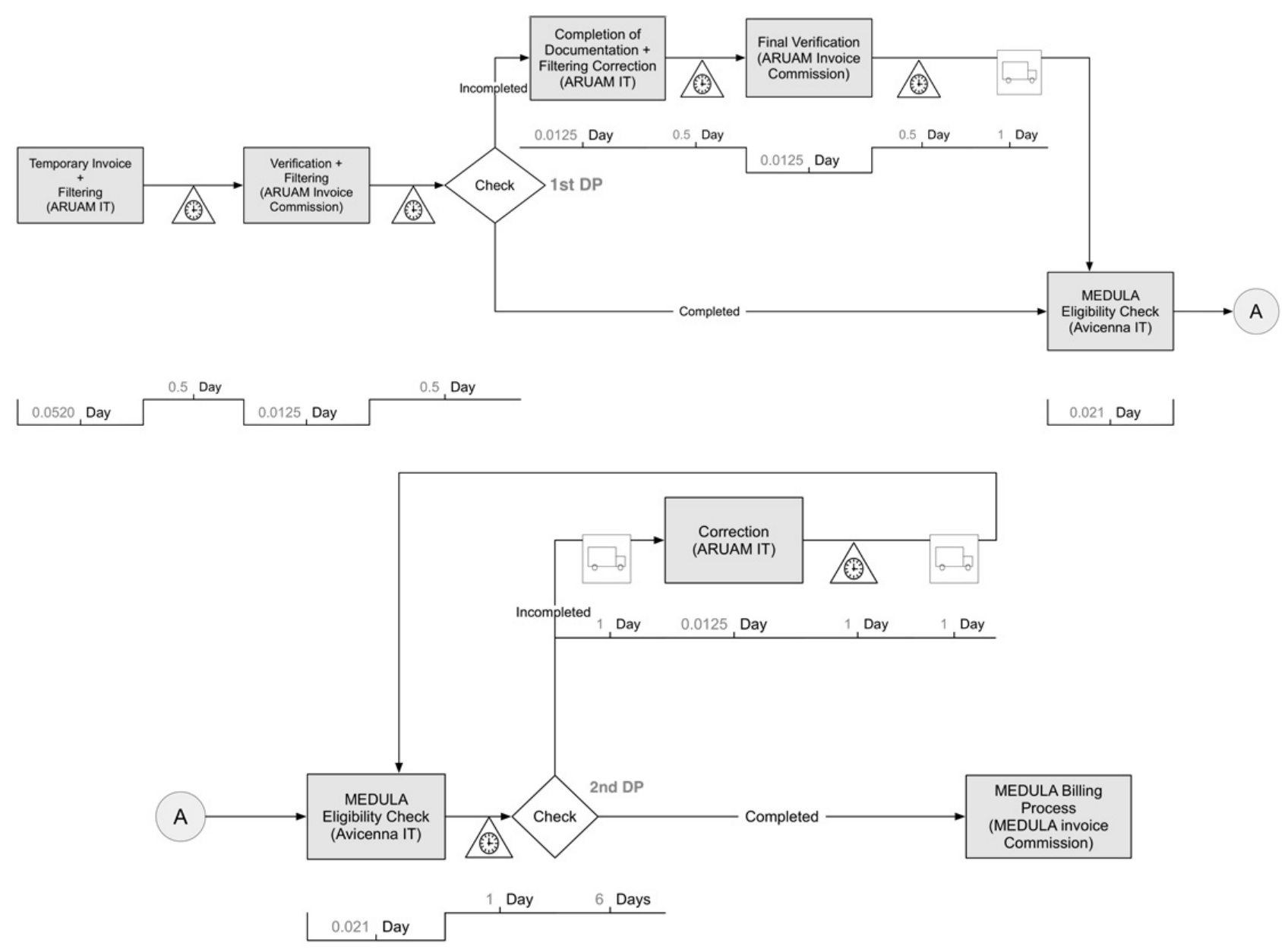

Figure 4. Value stream map after the lean transformation (future state)

Table 2. Times for each probable course of action in the value stream map (see Figure 4) after lean transformation

\begin{tabular}{llllll}
\hline Scenario & $\mathbf{1}^{\text {st }} \mathbf{D P}$ & $\mathbf{2}^{\text {nd }} \mathbf{D P}$ & Value Added (days) & Non-Value Added (days) & Total Duration (days) \\
\hline 1 & Incompeleted & Incompeleted & 0.119 & 14.025 & 14.144 \\
2 & Completed & Incompeleted & 0.106 & 12.012 & 12.119 \\
3 & Incompeleted & Completed & 0.098 & 10.012 & 10.110 \\
4 & Completed & Completed & 0.085 & 8.000 & 8.085 \\
\hline
\end{tabular}

Prior to lean transformation, there were four DP, which resulted in 16 probable courses of action in the value stream map. However, these probable routes have been reduced to four in consideration of two different DP in the value stream map after the study as depicted in Figure 4. Value added durations; non-value added durations and total durations have been given for each of four conditions on a decimal day basis time unit in Table 2.

Table 3 summarizes the values given in Table 1 and Table 2 . In Table 3, mean and standard deviation of the value added and non-value added durations for value stream maps shown in Figures 2 and 4 and the corresponding $p$-values for the $t$-tests are given. The invoicing process could be completed in an average of $67.69( \pm 4.05)$ days before the change took Published by Sciedu Press place, whereas after implementing the change, this has been reduced to an average of $11.11( \pm 2.61)$ days. The significant portion of the total duration were non-value added activities which were $67.55 \pm 4.07$ days, then reduced to $11.01 \pm 2.59$ days after the lean transformation.

\subsubsection{Standardization of tasks}

Standardization of tasks has to be accomplished for the processes for which the value stream mapping has been implemented. For that purpose, non-value added activities identified with mapping method should be removed from the existing job descriptions. Additionally, if there are jobs without any descriptions, new descriptions should be made appropriately. 
Table 3. Comparison of value-added and non-value added durations for before and after the lean tranformation

\begin{tabular}{llll}
\hline & $\begin{array}{l}\text { Before the lean transformation } \\
\text { (mean } \pm \text { dev.) }\end{array}$ & $\begin{array}{l}\text { After the lean transformation } \\
\text { (mean } \pm \text { dev.) }\end{array}$ & $\boldsymbol{p}$-value \\
\hline Value-added duration (days) & $0.17 \pm 0.01$ & $0.10 \pm 0.01$ & $<.001^{*}$ \\
Non-value added duration (days) & $67.55 \pm 4.07$ & $11.01 \pm 2.59$ & $<.001^{*}$ \\
Total Duration (days) & $67.69 \pm 4.05$ & $11.11 \pm 2.61$ & $<.001^{*}$ \\
\hline
\end{tabular}

Note. ${ }^{*}$ Statistically significant at .05 significance level

Standardization of tasks at hospitals provides an opportunity of business process re-engineering of these tasks and the respective personnel. In this scope, all of the job descriptions for all of the personnel have been re-engineered for the invoicing process at ARUAM. The missing job descriptions have been made; the missing parts of the existing job descriptions have been completed and necessary revisions have been done for the personnel assigned with new duties. The tasks and relevant descriptions in process flow diagrams have been paired and crosschecked.

\subsubsection{Proactive analysis of root causes for problems}

After implementation of correction steps for non-value added activities in the invoicing process, it is required to identify the root causes of the faults in order not to observe the same problems again. ${ }^{[20]}$ In this context, there are two important questions to be answered when faults are identified: (1) Why did these faults have occurred? (2) What can be done in order to have this fault never occur again?

In order to find the answer for the first question above or in other words to identify the root causes, cause and effect (fish bone) diagram method as indicated in Figure 5 have been used. All the faulty files of the patients have been inspected and the mistakes (inconsistencies with SSI rules) are classified in accordance with the type of files. In this respect, there are six different file types including faults, which are handled as separate categories in the diagram. Furthermore, sub-causes for fault occurrence for each of the six file types are identified and shown in the diagram. Besides, the responsible personnel for the file faults are determined and shown in parenthesis in the sub-causes part of the diagram.

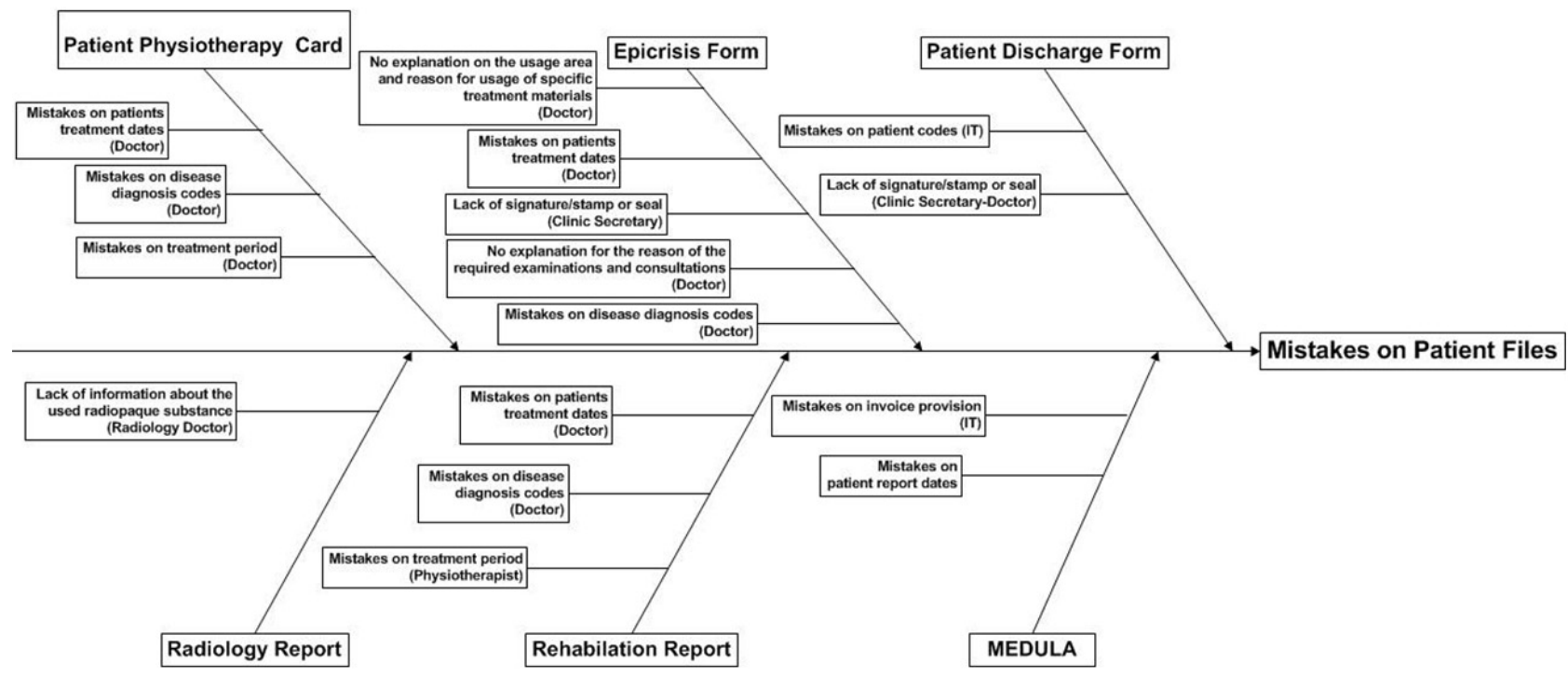

Figure 5. Root causes of faulty documentation and indications visually expressed in a cause and effect (fish bone) diagram

\subsubsection{Mistake proofing}

In order to provide services without faults, it is significant to identify the faults and make necessary corrections at their point of origin. For that reason, the sections of files are identified which are most prone to faults and poke-yoke type of file checklists have been generated that will ease the control of such possible faults. With these checklists, the institution is expected to conduct self-audits to decrease the occurrence of the faults at their point of origin. In consideration of this precautionary action, file checklists for clinicians, the clinic secretary and the IT clerk are included within the patient file.

\subsubsection{Kaizen}

In the scope of a lean transformation study, the focus is mainly on continuous improvements for not only implemen- 
tation of rapid improvements but also obtaining permanent success. For that purpose, in addition to the methods used so far, kaizen applications are performed at each step of the lean transformation study.
In Table 4, the kaizens implemented at lean transformation steps are given. The sub-processes for which improvements are made; the problem definitions for the relevant improvement efforts and the relevant improvements made for solving these problems are explained in Table 4.

Table 4. List of improvements accomplished at each step

\begin{tabular}{|c|c|c|}
\hline Process & Problem & Improvement \\
\hline Personnel Training & $\begin{array}{l}\text { Missing information regarding the new } \\
\text { tasks of invoice control unit in ARUAM }\end{array}$ & $\begin{array}{l}\text { Chief nurse, physical therapists, IT personnel, clinic and } \\
\text { polyclinic nurses have been trained for the invoice control. }\end{array}$ \\
\hline Quality team work & $\begin{array}{l}\text { Lack of coordination of the relevant } \\
\text { personnel in ARUAM for patient files }\end{array}$ & $\begin{array}{l}\text { A continuous improvement mechanism has been } \\
\text { established at ARUAM. The problems are solved at the } \\
\text { point of origin and the occurrence of new faults is } \\
\text { prevented. }\end{array}$ \\
\hline Quality team work & $\begin{array}{l}\text { No active quality study carried at } \\
\text { ARUAM }\end{array}$ & $\begin{array}{l}\text { Meetings for establishment of continuous improvement } \\
\text { plans are conducted. } 18 \text { meetings are organized during the } \\
\text { period of six months. }\end{array}$ \\
\hline $\begin{array}{l}\text { Preparation of physical } \\
\text { therapy and rehabilitation } \\
\text { treatment form }\end{array}$ & $\begin{array}{l}\text { Unpaid invoices due to inappropriate } \\
\text { charging for physical therapies done at } \\
\text { weekend }\end{array}$ & $\begin{array}{l}\text { The physical therapy and rehabilitation treatment form is } \\
\text { updated and a new section for weekend treatments is added } \\
\text { in accordance with SSI rules. }\end{array}$ \\
\hline $\begin{array}{l}\text { Discharging from the } \\
\text { hospital }\end{array}$ & $\begin{array}{l}\text { No discharge records are created for } \\
\text { some patients even } 2-3 \text { months after the } \\
\text { discharge }\end{array}$ & $\begin{array}{l}\text { The discharge of a patient is directly recorded in the } \\
\text { Avicenna. The patient file is forwarded to SUAM IT invoice } \\
\text { commission in } 2-7 \text { days after discharge. Then invoice is } \\
\text { generated in } 7 \text { days at most. }\end{array}$ \\
\hline $\begin{array}{l}\text { Preparation of physical } \\
\text { therapy and rehabilitation } \\
\text { report }\end{array}$ & $\begin{array}{l}\text { SSI Disapproval of the files due to } \\
\text { missing information in physical therapy } \\
\text { and rehabilitation reports. }\end{array}$ & $\begin{array}{l}\text { The physical therapy and rehabilitation report is updated } \\
\text { and new sections such as diagnosis, the part of the body that } \\
\text { the treatment is applied and the duration of the therapy are } \\
\text { included in the report in line with the requirements of SSI. }\end{array}$ \\
\hline Analyses & $\begin{array}{l}\text { No collection of payments for the } \\
\text { analyses done in the first day of the } \\
\text { hospitalization of the patient from SSI }\end{array}$ & $\begin{array}{l}\text { It is determined that no analysis should be conducted at the } \\
\text { very first day of hospitalization of the patient. }\end{array}$ \\
\hline
\end{tabular}

\section{Results}

In order to demonstrate the effect of the proposed lean studies on patient satisfaction, results of the before and after study patient satisfaction surveys are compared. The survey consisted of nine different questions and designed on a 5-point Likert scale, having positive responses with increasing score e.g. 1 denotes very poor or very unlikely and 5 denotes excellent or very likely. 117 and 91 patients participated in before and after study surveys respectively. The first five questions on the survey are mainly about the doctor, nurse and physiotherapist experience, where as the last four questions are for overall satisfaction. Of the participants who responded to the before study survey, there were 73 women and 44 men, while there were 56 women and 35 man participated in the after study survey. Moreover, both groups had similar age distribution. It should be noted that, the main idea behind the evaluations of the surveys is to analyze whether the proposed cost-concentrated lean studies have a negative effect on patient satisfaction or not.

Table 5 shows the main questions and the corresponding answers for the surveys. First, for a precise and pairwise comparison, statistical significances of the differences between the means of before and after study surveys are analyzed using $t$-tests where significance level is set to 0.05 . In the last column of Table 5, the p scores of corresponding t-tests are given. As can be seen from Table 5, the answers to the majority of questions remain unaffected with $\mathrm{p}$ values higher then 0.05. A statistically significant difference is observed only in answers to Question 9, which can be considered as an indirect positive effect of lean studies i.e. the workload reduction for invoice correction and control steps. As a result, one can surely conclude that the proposed lean transformation, which mainly aims to reduce the costs of services, do not have any negative effect on patient satisfaction and quality of healthcare. ${ }^{[36]}$ 
Table 5. Before and after study patient satisfaction survey results

\begin{tabular}{lllll}
\hline No & Question & Before study & After study & $p$-value \\
\hline 1 & Physiotherapists listened to me and spent enough time with me. & $4.09 \pm 0.53$ & $4.14 \pm 0.51$ & .49 \\
2 & Physiotherapists explained every step of my treatment & $3.74 \pm 0.46$ & $3.81 \pm 0.42$ & .26 \\
3 & Nurses listened to me and spent enough time with me. & $4.40 \pm 0.39$ & $4.33 \pm 0.31$ & .16 \\
4 & Doctor listened to me and spent enough time with me. & $3.19 \pm 0.37$ & $3.11 \pm 0.44$ & .16 \\
5 & Doctor gave enough explanation about the current & $3.49 \pm 0.48$ & $3.41 \pm 0.37$ & .19 \\
& conditions/medications/treatment. & & $4.17 \pm 0.29$ & .29 \\
6 & Facility was neat and clean. & $4.21 \pm 0.25$ & $2.79 \pm 0.41$ & .05 \\
7 & It was easy to find where to go in the facility. & $3.15 \pm 0.32$ & $3.94 \pm 0.24$ & $<.01^{*}$ \\
8 & The time spent in the facility was what I expected. & $4.11 \pm 0.27$ & $4.15 \pm 0.33$ & .34 \\
9 & Overall satisfaction. & & &
\end{tabular}

Second, the ratio of SSI cuts, which shows the percentage of faulty invoices over the total of submitted invoices, is analyzed to demonstrate the effectiveness of the lean approaches. The monthly variation of SSI cuts due to invoice processing mistakes in patient files for an 18-month period is summarized in Figure 6. Furher, the normalized income values for the hospital is also plotted as a second axis for the same time range. Here, it should be noted that proposed study has been carried out between Months 6 and 12. As noticeable in
Figure 6, a continuous reduction is observable for the months of the ongoing study and percentage of SSI cuts is reduced to zero at the end of the study, resulting in a total reduction of $8 \%$ approximately. On the other hand, a clear increase is obtained for the hospital overall income values starting from Month 7 to Month 13. Therefore, it can be concluded that the invoicing process of ARUAM is improved and implementing the proposed lean study reduces corresponding costs.

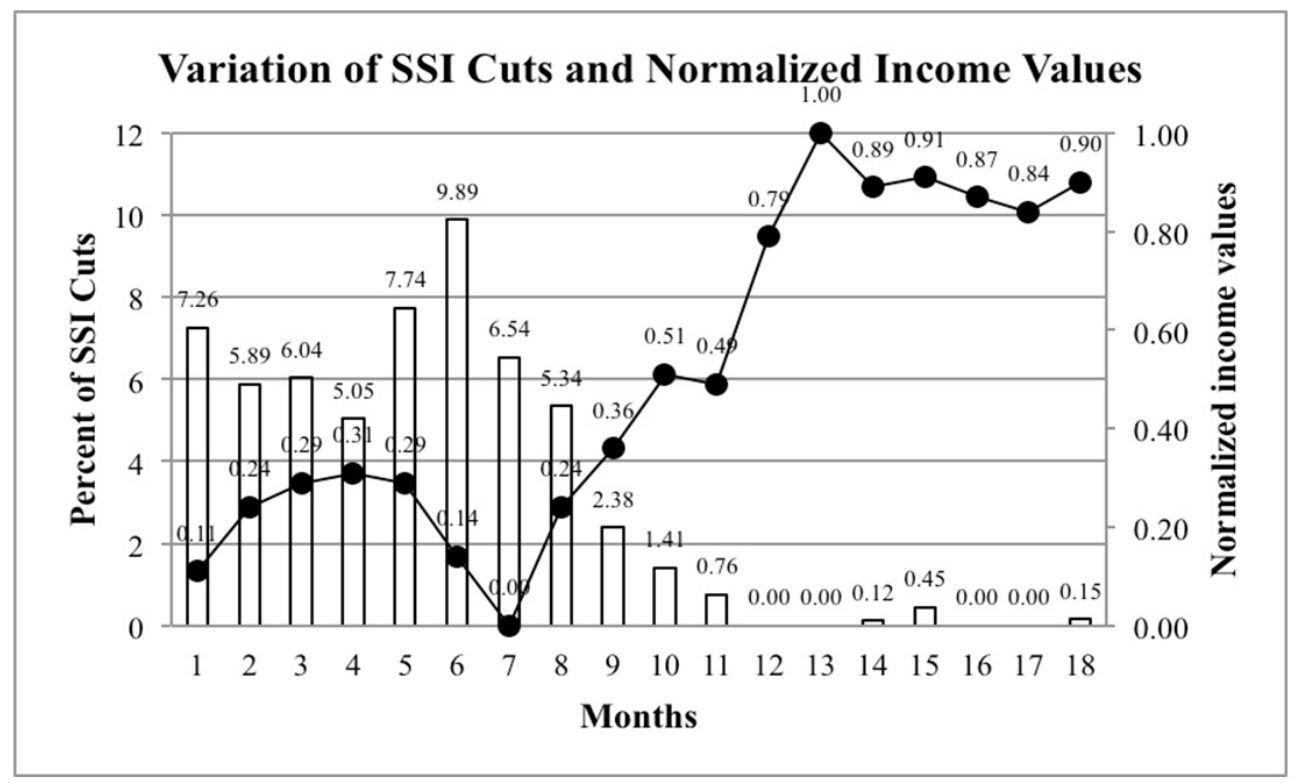

Figure 6. Percentage of SSI cuts and hospital income values with respect to months

\section{DISCUSSION AND CONCLUSIONS}

The main goal of this study is to improve the patient treatment related invoicing process of a university hospital and thereby reduce the incurring financial losses due to faulty and/or delayed reimbursement application files. In this study, process improvements are handled within a lean transformation approach utilizing lean techniques. Identification and elimination of some critical non-value added activities within the invoicing process easily proved that the overall process duration could be reduced from $67.69 \pm 4.05$ days to $11.11 \pm 2.61$ days after the implementation of the study. During the study, elimination of non-value added workloads of the personnel required their job descriptions to be revised also. The root causes of existing faults in the process are in- 
vestigated in detail and quality is maintained at the source via mistake proofing in order not to confront with the same problems again. Furthermore, kaizen's have been done at each step of the improvement efforts for a variety of problems by achieving permanent success. An $8 \%$ reduction in SSI cuts and income improvement are achieved as a result of implementing aforementioned lean tools. Moreover, proposed study highlights the implementation of lean techniques in order to reduce costs in healthcare processes, while maintaining the patient satisfaction levels. The study was conducted at a small-sized public hospital in Bursa, Turkey, which limits the generalizability of the obtained results to other hospitals or clinics. Another weakness of the study is that the survey questions could not be linked to improvements obtained by lean studies, since the standard patient satisfaction survey was not updated and lean specific questions were not added

\section{REFERENCES}

[1] Turkstat. Health Expenditure Statistics 1999-2014. Turkish Statistical Institute; 2015.

[2] WHO. World Health Statistics - 2015. World Health Organization; 2015.

[3] OECD. Health Statistics - 2015. OECD Publishing; 2015.

[4] Ohno T. Toyota production system: beyond large-scale production: crc Press; 1988.

[5] Womack JP, Jones DT. Lean thinking: banish waste and create wealth in your corporation: Simon and Schuster; 2010.

[6] Young T, McClean S. A critical look at Lean Thinking in healthcare. Quality and Safety in Health Care. 2008; 17(5): 382-6. PMid: 18842980. https://doi.org/10.1136/qshc.2006.020131

[7] Graban M. Lean hospitals: Improving quality, patient safety, and employee engagement: CRC press; 2011.

[8] Rother M, Shook J. Learning to see: value stream mapping to add value and eliminate muda: Lean Enterprise Institute; 2003.

[9] Krijnen A. The Toyota way: 14 management principles from the world's greatest manufacturer. 2007.

[10] Teichgräber UK, de Bucourt M. Applying value stream mapping techniques to eliminate non-value-added waste for the procurement of endovascular stents. European journal of radiology. 2012; 81(1): e47-e52. PMid: 21316173. https://doi.org/10.1016/j.ejra d.2010.12.045

[11] Snyder KD, Paulson P, McGrath P. Improving processes in a small health-care network: A value-mapping case study. Business Process Management Journal. 2005; 11(1): 87-99. https://doi.org/10 $.1108 / 14637150510578755$

[12] Dickson EW, Singh S, Cheung DS, et al. Application of lean manufacturing techniques in the emergency department. The Journal of emergency medicine. 2009; 37(2): 177-82. PMid: 18722732. https://doi.org/10.1016/j.jemermed.2007.11.108

[13] Cima RR, Brown MJ, Hebl JR, et al. Use of lean and six sigma methodology to improve operating room efficiency in a high-volume tertiary-care academic medical center. Journal of the American College of Surgeons. 2011; 213(1): 83-92. PMid: 21420879. https: //doi.org/10.1016/j.jamcollsurg.2011.02.009 to the survey before the beginning of the lean transformation. Lastly, small sample size in patient satisfaction surveys limited our ablility to examine the results in details. Future research may include extending these tools and techniques to entire hospital processes and more comparisons may be carried out between different public hospitals to demonstrate the effectiveness of lean thinking.

\section{ACKNOWLEDGEMENTS}

The authors would like to thank the anonymous referees for their helpful comments and suggestions on improving the presentation of this paper. This work is partially supported by Uludag University Scientific Research Council under the Grant no. BUAP(T) 2012/2.

\section{CONFliCtS OF INTEREST Disclosure}

The authors declare they have no conflict of interest.
[14] Dickson EW, Anguelov Z, Vetterick D, et al. Use of lean in the emergency department: a case series of 4 hospitals. Annals of emergency medicine. 2009; 54(4): 504-10. PMid: 19423187. https: //doi.org/10.1016/j. annemergmed.2009.03.024

[15] Doğan NÖ, Unutulmaz O. Lean production in healthcare: a simulation-based value stream mapping in the physical therapy and rehabilitation department of a public hospital. Total Quality Management \& Business Excellence. 2016; 27(1-2): 64-80. https: //doi.org/10.1080/14783363.2014.945312

[16] Weigel C, Suen W, Gupte G. Using lean methodology to teach quality improvement to internal medicine residents at a safety net hospital. American journal of medical quality: the official journal of the American College of Medical Quality. 2013; 28(5): 392-9. https://doi.org/10.1177/1062860612474062

[17] Joosten T, Bongers I, Janssen R. Application of lean thinking to health care: issues and observations. International Journal for Quality in Health Care. 2009; 21(5): 341-7. PMid: 19696048. https://doi.org/10.1093/intqhc/mzp036

[18] Van Vliet EJ, Bredenhoff E, Sermeus W, et al. Exploring the relation between process design and efficiency in high-volume cataract pathways from a lean thinking perspective. International Journal for Quality in Health Care. 2011; 23(1): 83-93. PMid: 21123187. https://doi.org/10.1093/intqhc/mzq071

[19] Jimmerson C, Weber D, Sobek DK. Reducing waste and errors: piloting lean principles at Intermountain Healthcare. The Joint Commission Journal on Quality and Patient Safety. 2005; 31(5): 249-57. https://doi .org/10.1016/S1553-7250(05) 31032-4

[20] King DL, Ben-Tovim DI, Bassham J. Redesigning emergency department patient flows: application of Lean Thinking to health care. Emergency Medicine Australasia. 2006; 18(4): 391-7. PMid: 16842310 https://doi.org/10.1111/j.1742-6723.2006.00872.x

[21] Ben-Tovim DI, Bassham JE, Bolch D, et al. Lean thinking across a hospital: redesigning care at the Flinders Medical Centre. Australian Health Review. 2007; 31(1): 10-5. PMid: 17266483. https : //doi.org/10.1071/AH070010 
[22] Vats A, Goin $\mathrm{KH}$, Villarreal $\mathrm{MC}$, et al. The impact of a lean rounding process in a pediatric intensive care unit. Crit Care Med. 2012; 40(2): 608-17. https://doi.org/10.1097/CCM. 0b013e318232e2f c

[23] Waldhausen JH, Avansino JR, Libby A, et al. Application of lean methods improves surgical clinic experience. Journal of pediatric surgery. 2010; 45(7): 1420-5. PMid: 20638518. https://doi.or $\mathrm{g} / 10.1016 / \mathrm{j} \cdot$ jpedsurg. 2009.10.049

[24] LaGanga LR. Lean service operations: reflections and new directions for capacity expansion in outpatient clinics. Journal of Operations Management. 2011; 29(5): 422-33. https://doi.org/10.1016/ j.jom.2010.12.005

[25] Raab SS, Andrew-JaJa C, Condel JL, et al. Improving Papanicolaou test quality and reducing medical errors by using Toyota production system methods. American journal of obstetrics and gynecology. 2006; 194(1): 57-64. PMid: 16389010. https://doi.org/10.1 016/j.ajog. 2005.06.069

[26] Spear SJ. Fixing health care from the inside, today. Harvard business review. 2005; 83(9): 78. PMid: 16171213.

[27] Yousri T, Khan Z, Chakrabarti D, et al. Lean thinking: Can it improve the outcome of fracture neck of femur patients in a district general hospital? Injury. 2011; 42(11): 1234-7. PMid: 21227417. https://doi.org/10.1016/j.injury. 2010.11.024

[28] Vegting IL, van Beneden M, Kramer MH, et al. How to save costs by reducing unnecessary testing: lean thinking in clinical practice. Eur J Intern Med. 2012; 23(1): 70-5. https ://doi .org/10.1016/j . ejim.2011.07.003
[29] Brandao de Souza L. Trends and approaches in lean healthcare. Leadership in Health Services. 2009; 22(2): 121-39. https ://doi.or $\mathrm{g} / 10.1108 / 17511870910953788$

[30] Burgess N, Radnor Z. Evaluating Lean in healthcare. Int J Health Care Qual Assur. 2013; 26(3): 220-35. https://doi.org/10.110 8/09526861311311418

[31] Holden RJ. Lean Thinking in emergency departments: a critical review. Ann Emerg Med. 2011; 57(3): 265-78. https ://doi.org/ $10.1016 / j$. annemergmed. 2010.08 .001

[32] Mazzocato P, Savage C, Brommels M, et al. Lean thinking in healthcare: a realist review of the literature. Quality \& safety in health care. 2010; 19(5): 376-82. https://doi.org/10.1136/qshc.2 009.037986

[33] Nicolay C, Purkayastha S, Greenhalgh A, et al. Systematic review of the application of quality improvement methodologies from the manufacturing industry to surgical healthcare. British Journal of Surgery. 2012; 99(3): 324-35. PMid: 22101509. https://doi.org/10.1 $002 /$ bjs. 7803

[34] Toussaint JS, Berry LL. The promise of Lean in health care. Mayo Clinic proceedings. 2013; 88(1): 74-82. https ://doi . org/10.1 016/j . mayocp. 2012.07.025

[35] Costa LBM, Godinho Filho M. Lean healthcare: review, classification and analysis of literature. Production Planning \& Control. 2016: 1-14. https://doi.org/10.1080/09537287.2016.1143131

[36] Ozdemir D. Improvement of healthcare processes by lean techniques [M.Sc. Thesis]. Bursa, Turkey: Institute of Natural Sciences, Uludag University; 2013. 